\title{
Potassium Ions Release from Polysaccharide Films
}

\author{
Aline F. Oliveira, ${ }^{a}$ Cristian B. Silveira, ${ }^{b}$ Paulo R. Ernani, ${ }^{b}$ Elisandro S. Balbinot ${ }^{b}$ and \\ Valdir Soldi ${ }^{*, a}$
}

\author{
${ }^{a}$ Grupo de Estudos em Materiais Polimericos, Departamento de Quimica, \\ Universidade Federal de Santa Catarina, 88040-900 Florianopolis-SC, Brazil
}

${ }^{b}$ Departamento de Solos, Universidade do Estado de Santa Catarina, 88520-000 Lages-SC, Brazil

\begin{abstract}
Em meios para crescimento de plantas deficientes em cargas negativas, o potássio $(\mathrm{K})$ é facilmente lixiviado com consequiências adversas quanto a sua disponibilidade para as plantas e para o meio ambiente, uma vez que todos os fertilizantes a base de K são completamente solúveis. O objetivo deste estudo foi preparar filmes a partir da carboximetilcelulose de sódio (CMC), alginato de sódio (AS) e da mistura 1:1 (v/v) CMC:AS para incorporação de K e investigar a sua posterior liberação. As propriedades do filmes foram avaliadas considerando a miscibilidade, a temperatura de transição vítrea, morfologia e permeação de potássio. A ausência de interações fortes, a pequena variação na temperatura de transição vítrea e a rugosidade detectada nas micrografias da secção transversal em filmes da mistura CMC:AS (1:1), indicaram miscibilidade parcial entre os componentes. Como conseqüência das características acima mencionadas, a liberação de potássio foi maior em filmes da mistura CMC:AS (1:1) e menor para a AS. O mecanismo de liberação de $\mathrm{K}$ da mistura CMC:AS (1:1) foi controlada por um processo de difusão, no entanto, efeitos associados ao intumescimento e erosão da matriz, foram observados para os sistemas CMC e AS puros. Filmes de CMC, AS e a mistura (1:1) foram capazes de reduzir a velocidade de liberação de $\mathrm{K}$, podendo trazer benefícios consideráveis em termos do crescimento das plantas quando são utilizados meios deficientes em cargas negativas.
\end{abstract}

In plant growth media of low negative charge, potassium $(\mathrm{K})$ is leached out easily with adverse consequences on its availability to plants and on the environment, since all $\mathrm{K}$ fertilizers are completely soluble. The objective of this study was to prepare films based on sodium carboxymethylcellulose (CMC), sodium alginate (SA) and a 1:1 (v/v) CMC:SA mixture to incorporate $\mathrm{K}$ and investigate its subsequent release. The film properties were evaluated considering miscibility, glass transition temperature, morphology and permeation of potassium. The absence of strong interactions, the small variation in the glass transition temperature and the roughness detected in the cross-section micrographs of the 1:1 CMC:SA mixtures, indicated a partial miscibility among the components. As a consequence of the above-mentioned characteristics, film release of potassium was highest for the 1:1 CMC:SA mixture and lowest for SA. The release mechanism of $\mathrm{K}$ from the 1:1 CMC:SA mixture was controlled by a diffusion process, however, associated effects due to swelling and erosion of the matrix films, were observed for the pure CMC and SA systems. Films of CMC, SA and their 1:1 mixture were able to delay the K release, which can bring considerable benefits in terms of plant growth when media with low negative charges are used.

Keywords: carboxymethylcellulose, sodium alginate, potassium release, biodegradable polymers

\section{Introduction}

Natural polymers like polysaccharides have been extensively studied due to their applications and characteristics including low cost, non-toxicity, biodegradability and

*e-mail: vsoldi@qmc.ufsc.br biocompatibility. Two commonly employed examples are carboxymethylcellulose (CMC) and sodium alginate (SA). Sodium alginate is an anionic polysaccharide, extracted from brown algae, which consists of $\alpha$-L-guluronic acid and $\beta$-D-mannuronic acid substitutents. ${ }^{1}$ Carboxymethylcellulose is an ionic ether derived from cellulose and, in general, it is considered a low cost polysaccharide when compared with 
sodium alginate. ${ }^{2}$ Our interest in these particular polysaccharides lies in the fact that they can be used to make films, ${ }^{3-6}$ gels, ${ }^{7}$ hydrogels (after crosslinking with polyvalent metals) ${ }^{2,8-10}$ and beads. ${ }^{11-13}$ They have been most notably used in the pharmaceutical area to control the rate of drug release. ${ }^{1,6,7,14}$ Recently, their applications were extended to the agricultural area, to control the release of pesticides ${ }^{11-13}$ and plant nutrients. ${ }^{10}$ Controlled-release has several advantages including: $(i)$ activity prolongation, by providing continuous low amounts of agrochemicals (for example, nutrients) at levels sufficient for their functions to be performed over a long period; (ii) reduction in the number of applications by increasing the period of activity of such products; and (iii) cost reduction, by decreasing the time and the cost of repeated applications. ${ }^{15-18}$

Potassium $(\mathrm{K})$ is the second most important plant nutrient in terms of quantities required, nitrogen being the first. In the soil, a small part of $\mathrm{K}$ is present in solution in the soil water, which is the medium from which the plants take up nutrients. Most of the available fraction of $\mathrm{K}$ is electrostatically adsorbed to negative electric charges located on the surfaces of clay minerals and organic components of the soil. To maintain an adequate ratio between adsorbed and solution $\mathrm{K}$ it is important not only to guarantee the appropriate supply of K to the plants but also to avoid excessive losses of $\mathrm{K}$ through leaching. In highly weathered soils, like those occurring in most Brazilian regions, as well as in certain medium used for growing plants in protected environments, the number of negative electric charges is small. Under these conditions, addition of high rates of soluble $\mathrm{K}$ fertilizers may result in excessive leaching. Thus, the use of products that delay the release of $\mathrm{K}$ to the soil solution is important from both the economic and environmental point of view.

The main purpose of this study was to evaluate the release of $\mathrm{K}$ (from KCl) incorporated in CMC, SA and 1:1 CMC:SA films to a sand medium and its subsequent release from the leaching columns.

\section{Experimental}

\section{Materials}

The polymers (sodium carboxymethylcellulose, DS $=7$ and $\mathrm{M}_{\mathrm{w}} 250000 \mathrm{~g} \mathrm{~mol}^{-1}$, and sodium alginate) used to prepare the films were purchased from Acros Organics. The potassium chloride used in the films was purchased from Nuclear. All materials were used without further purification.

\section{Film preparation}

The films were prepared by dissolution of sodium carboxymethylcellulose (CMC) and sodium alginate (SA) in deionized water $(\mathrm{pH}=6.7 \pm 0.2)$, at room temperature, in a concentration of $2 \%(\mathrm{~m} / \mathrm{v})$. The 1:1 CMC:SA mixture was prepared by mixing equal volumes of the two polymers. After shaking for $24 \mathrm{~h}$, the solutions were transferred to polystyrene petri dishes, where they remained under uncontrolled environmental conditions for around $48 \mathrm{~h}$ for solvent evaporation (casting process). Film thickness was controlled by casting the same amount $(50 \mathrm{~mL})$ of film-forming solution in each polystyrene Petri dish. After this time, the residual water was removed in a vacuum oven, at room temperature, for $24 \mathrm{~h}$, and the films were stored in desiccators until analysis.

For the incorporation process, 120 or $240 \mathrm{mg}$ of $\mathrm{K}$ (from $\mathrm{KCl}$ ) was added to the film-forming solution of CMC, SA and the 1:1 CMC:SA mixture. The films were obtained by casting as described above.

\section{FTIR spectroscopy}

Fourier transform infrared spectroscopy (FTIR) was carried out on a Bomem spectrometer, model FTLA 2000, with a resolution of $4 \mathrm{~cm}^{-1}$, in the range of $4000-400 \mathrm{~cm}^{-1}$. Films were prepared in a concentration of $0.2 \%(\mathrm{~m} / \mathrm{v})$.

\section{Thermomechanical analysis}

In order to determine the glass transition temperature $\left(\mathrm{T}_{\mathrm{g}}\right)$, experiments in expansion mode were carried out on a thermomechanical analyzer (TMA 50, Shimadzu). Triplicate samples of $10 \times 5 \mathrm{~mm}$ were first heated from 25 to $110^{\circ} \mathrm{C}$ at $10^{\circ} \mathrm{C} \mathrm{min}{ }^{-1}$, for water elimination. After being cooled to room temperature the samples were re-heated from 30 to $200{ }^{\circ} \mathrm{C}$ at $10^{\circ} \mathrm{C} \mathrm{min}^{-1}$. Both scans were obtained

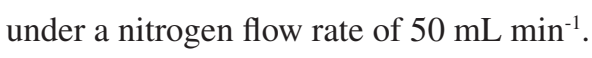

\section{SEM}

The morphology of the surfaces and cross-section (fractured under liquid nitrogen) of the films, with and without potassium load, was analyzed using a Philips scanning electron microscope (SEM), model XL30, equipped with an energy dispersive spectroscopy (EDS) accessory. Before analysis, samples were coated with a thin layer of gold.

\section{Release process}

The amount of potassium incorporated into the films was evaluated through the Adler \& Wilcox methodology ${ }^{19}$ with small modifications. The films (1.22 g) with potassium were solubilized in $500 \mathrm{~mL}$ of water by stirring for $24 \mathrm{~h}$. After this period, aliquots of $15 \mathrm{~mL}$ were transferred to digestion tubes, in which $2 \mathrm{~mL}$ of sulfuric acid $\left(\mathrm{H}_{2} \mathrm{SO}_{4}\right)$ and $3 \mathrm{~mL}$ of 
hydrogen peroxide $\left(\mathrm{H}_{2} \mathrm{O}_{2}\right)$ were added. The tubes were placed in a digestor block initially adjusted to $100{ }^{\circ} \mathrm{C}$, subsequently warmed at $1{ }^{\circ} \mathrm{C} \mathrm{min}{ }^{-1}$ to $350{ }^{\circ} \mathrm{C}$, and then maintained at this temperature. After $60 \mathrm{~min}, 3 \mathrm{~mL}$ of $\mathrm{H}_{2} \mathrm{O}_{2}$ were added and the tubes were maintained at $350{ }^{\circ} \mathrm{C}$ for a further $90 \mathrm{~min}$. The tubes were removed from the digestor for cooling, filled up to $50 \mathrm{~mL}$ with distilled water and the potassium content (triplicate samples) was determined by flame photometry (Mod. DIGIMED DM-61). The loading efficiency was calculated using equation 1.

Loading Efficiency $(\%)=\left(\frac{\text { Loading } \text { mass }}{\text { Initial } \text { mass }}\right) \times 100$

The films containing $\mathrm{K}$ were mixed with pure sand in order to evaluate the release of potassium to this medium. Since sand does not have a significant amount of negative charges, or other types of adsorption sites, all $\mathrm{K}$ released remains in the sand water. Two experiments were carried out. In the first one, films with $120 \mathrm{mg}$ of $\mathrm{K}$ incorporated, in addition to those treated with $120 \mathrm{mg}$ of $\mathrm{K}$ from $\mathrm{KCl}$ and with no $\mathrm{K}$ (control), were homogenously mixed with $2.0 \mathrm{~kg}$ of natural sand and subsequently placed in PVC leaching columns $(30 \mathrm{~cm}$ length and $10 \mathrm{~cm}$ in diameter). Subsequently, $\mathrm{K}$ was percolated from the columns through 22 successive additions of distilled water, each one consisting of $200 \mathrm{~mL}$ per column, performed at intervals of 2.5 days. The second experiment used the same methodology and treatments consisted of addition of two K loads (120 and $240 \mathrm{mg}$ ) incorporated into 1:1 CMC: SA films and free $\mathrm{K}$ in the form of $\mathrm{KCl}$.

During the percolations, distilled water was added at the top of each leaching column at a rate of approximately $5 \mathrm{~mL}$ per min. A plastic flask was placed below each column to collect the percolated solution. The volume of the effluent was measured and the concentration of $\mathrm{K}$ in it was determined on a flame photometer (DIGIMED).

\section{Results and Discussion}

\section{FTIR analysis}

The FTIR spectra of the 1:1 CMC:SA mixture was compared with the pure components in Figure 1. In both spectra (pure components and mixture), a wide absorption band between $3800-3000 \mathrm{~cm}^{-1}$, associated with free and bonded hydroxyl groups, was observed. ${ }^{2,10,20}$ Asymmetric bands associated with $\mathrm{C}=\mathrm{O}$ stretching (carboxyl groups) were observed at 1608, 1597 and $1604 \mathrm{~cm}^{-1}$ for the CMC, SA and 1:1 CMC:SA mixture, respectively. For the same systems, the corresponding symmetric $\mathrm{C}-\mathrm{O}$ stretching was observed at 1415,1418 and $1415 \mathrm{~cm}^{-1}$, respectively., ${ }^{2,8,11}$ The bands at $1325 \mathrm{~cm}^{-1}$ (CMC) and $1300 \mathrm{~cm}^{-1}(\mathrm{SA})$ attributed to $\mathrm{C}-\mathrm{O}$ stretching, shifted to $1324 \mathrm{~cm}^{-1}$ for the 1:1 CMC:SA, closer to the absorption of CMC. A strong band due to the ether group ( $\mathrm{C}-\mathrm{O}-\mathrm{C}$ stretching) was observed at $1063 \mathrm{~cm}^{-1}$ (with a shoulder at $1035 \mathrm{~cm}^{-1}$ ) for CMC. The same stretching occurred at $1035 \mathrm{~cm}^{-1}$ for the SA and 1:1 CMC:SA mixture. The characteristics of the FTIR spectra for the pure components and 1:1 mixture showed only small shifts in the absorption bands, in addition to the absence of bands at 1700-1730 and 1180-1250 $\mathrm{cm}^{-1}$ associated with ester bonds, suggesting that the interactions between the two polysaccharides were mainly of the hydrophobic type, i.e., no chemical bonds were established between the components. Similar behavior has been described in the literature for other systems, such as, hydroxypropylmethylcellulose/sodium carboxymethylcellulose $\mathrm{e}^{21}$ and hydroxylethyl-cellulose/sodium carboxymethylcellulose. $^{20}$

The glass transition temperatures, considering the variation in the linear thermal expansion coefficients of the films, were practically the same (range $137-140{ }^{\circ} \mathrm{C}$ ) for the pure components and the 1:1 CMC:SA mixture. These values are in agreement with the small shifts of the absorption bands observed in the FTIR spectra (Figure 1), confirming the absence of interactions between the components.

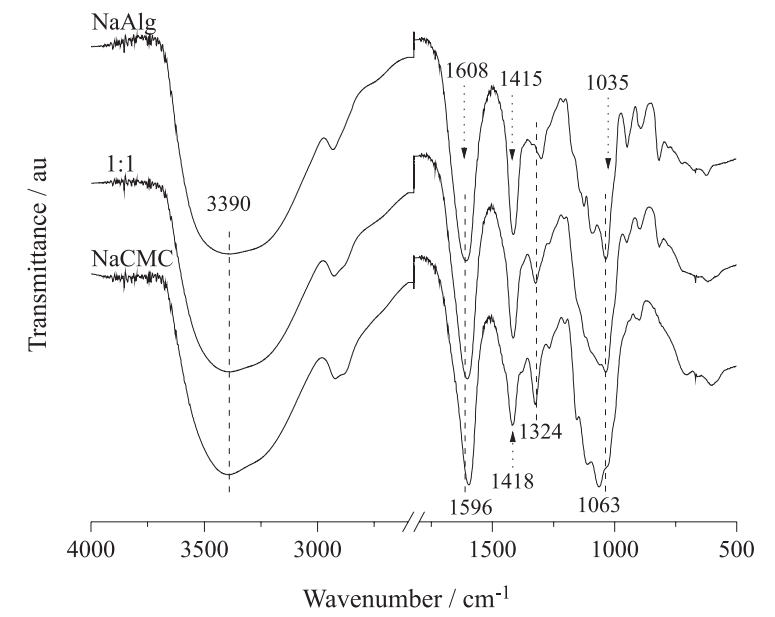

Figure 1. FTIR spectra of films of sodium carboxymethylcellulose, sodium alginate and their 1:1 mixture $(\mathrm{v} / \mathrm{v})$.

SEM

The films of CMC and SA, in the absence of potassium (micrographs not shown), were dense, smooth and homogeneous, suggesting a total absence of porosity. At the same time, for the 1:1 CMC:SA mixture, both the surface and cross-section showed some roughness and a slightly heterogeneous morphology, which can be attributed to the absence of interactions between the two polymers, as previously observed by FTIR. In the case of the cross-section micrographs of CMC, SA and 1:1 CMC:SA films loaded with 
$120 \mathrm{mg}$ of potassium (Figure 2), it is possible to observe a dense layer of $\mathrm{KCl}$ crystals, mainly located on the surfaces of the films. Particularly, for the CMC (Figure 2A), a great number of small $\mathrm{KCl}$ crystals were observed dispersed in a homogeneous cross-section. The small crystals were probably formed due to the casting process starting from the outer region (solution surface), suggesting that the solution from the inner region must migrate to the surface before evaporation, leading to a higher crystal concentration close the film surface. From the EDS analysis, the amount of potassium loaded in the crosssection of the CMC films was estimated as $26.6 \%$ from the total of the detected ions. The cross-section micrograph of SA films (Figure 2C) shows that the potassium was preferentially distributed in the region close to the surface. For this system, the estimated percentage of potassium loaded in the film was $37.7 \%$, i.e., approximately $10 \%$ more than the percentage estimated for the CMC film.

A different behavior was observed for the 1:1 CMC:SA films (Figure 2B). The potassium loading ( $c a .45 \%$, estimated by EDS analysis) and the crystal distribution along the cross-section appear to have been favored by the roughness and heterogeneity of the system. Both of these characteristics are particularly desirable in terms of increases in the release of $\mathrm{K}$ in the soil.

\section{Release of potassium from the films}

The loading efficiencies, determined using equation 1 , were in the range of $80-85 \%$ for the systems containing $120 \mathrm{mg}$ of $\mathrm{K}$ which corresponds to $100 \mathrm{mg}$ incorporated. For the systems containing $240 \mathrm{mg}$ of $\mathrm{K}$, the percentage of potassium incorporated into the films was almost the same (ca. 86\%), corresponding to $206 \mathrm{mg}$. For the loading process, $\mathrm{KCl}$ was added to the film-forming solution and, as observed by SEM, the crystals were mainly distributed on the surface of the films. Although the micrographs for the 1:1 CMC/AS film showed the greatest roughness (see micrograph in Figure 2), the percentage of K loaded was almost the same for all systems.

Figure 3 shows the profiles of K (120 mg) release from CMC, SA and 1:1 CMC:SA films and the subsequent percolation in pure sand in comparison with free $\mathrm{K}$ from $\mathrm{KCl}$. The curves fitted well $\left(r^{2} \geq 0.98\right)$ with a first order exponential equation (dotted lines). After 55 days, 25, 35 and $46 \mathrm{mg}$ of $\mathrm{K}$ were released to the medium from $\mathrm{SA}, \mathrm{CMC}$ and 1:1 CMC:SA films, respectively. The higher percolation observed for 1:1 CMC:SA is due to the greater roughness characteristic of this film in relation to CMC and SA (Figure 2). In a previous study we analyzed the water vapor permeation in $\mathrm{CMC}$, SA and 1:1 CMC:SA films at different moisture contents and we observed the highest values for the 1:1 mixture. ${ }^{22}$ Within the
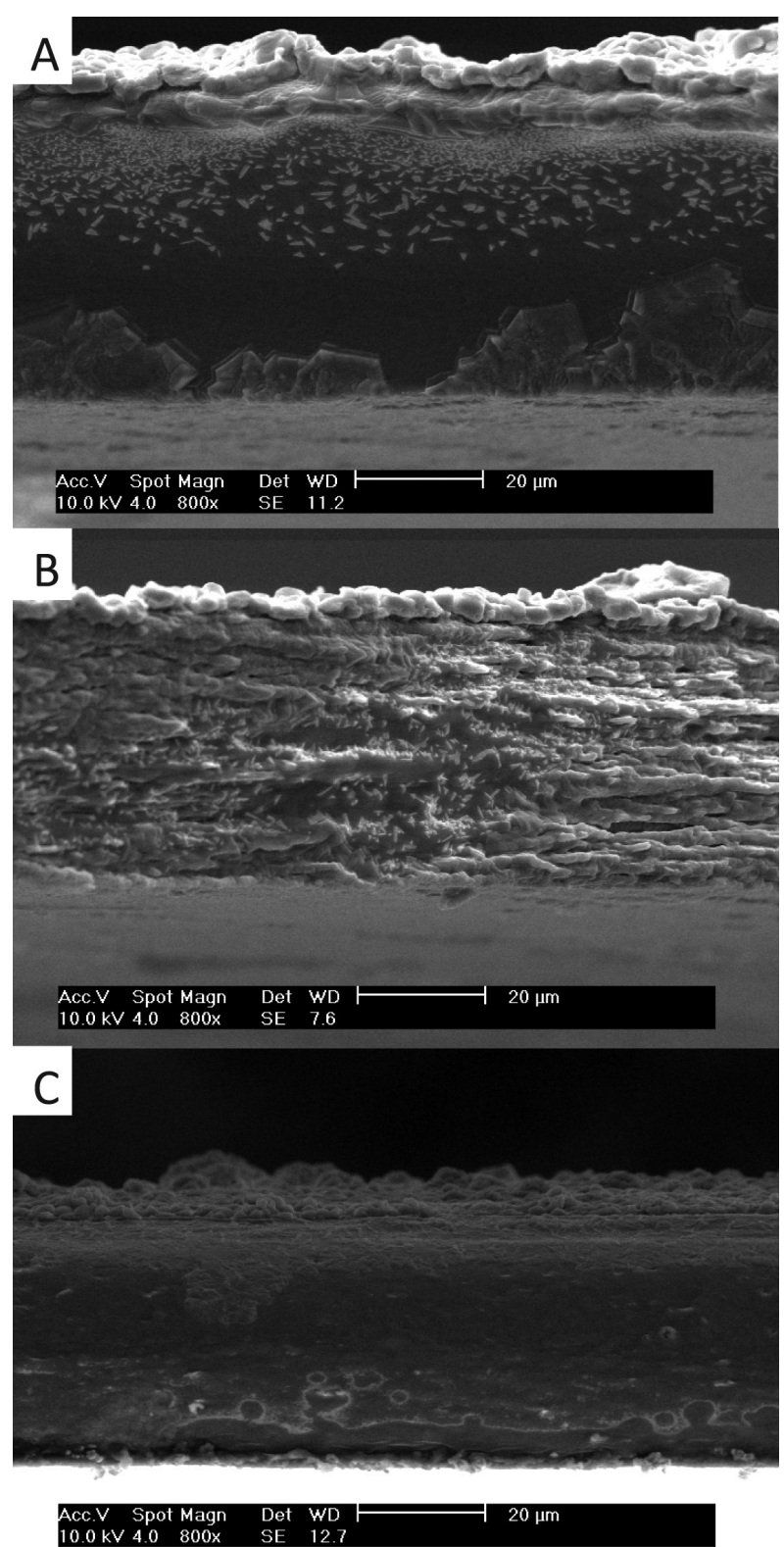

Figure 2. Cross-section micrographs for: A) CMC; B) 1:1 CMC:SA mixture and C) SA films with $120 \mathrm{mg}$ of loaded potassium.

same period of time (55 days), percolation of free potassium in sand achieved ca. $120 \mathrm{mg}$, with $70 \%$ (85 mg) released in the first 10 days (first 5 percolations). Fast percolation is undesirable since it favors leaching of $\mathrm{K}$ before it can be taken up by plants. However, the release rate of $\mathrm{K}$ from the polymeric films was low, since only $20 \mathrm{mg}$ of $\mathrm{K}$ was released from the 1:1 CMC: SA film in the first 10 days. The characteristics of the profiles also indicated a slower release of $\mathrm{K}$ from the films in relation to that provided by $\mathrm{KCl}$, suggesting a better availability of $\mathrm{K}$ to the plants over time.

A second experiment was performed comparing the percolation of 120 and $240 \mathrm{mg}$ of $\mathrm{K}$ from 1:1 CMC:SA films and of free K (Figure 4). The dotted lines in Figure 4 


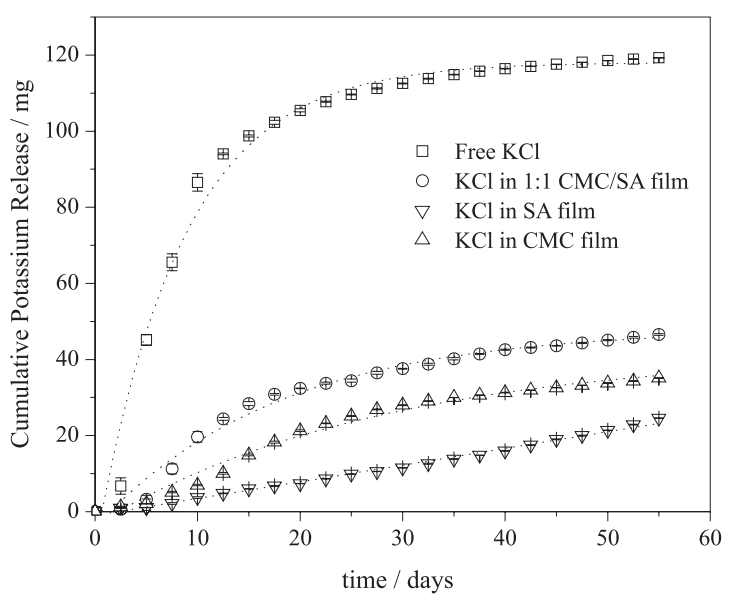

Figure 3. Release profiles of $\mathrm{K}(120 \mathrm{mg})$ from CMC, SA and 1:1 CMC:SA films and free $\mathrm{K}$ in sand soil.

represent the best fit curve, considering a first-order exponential equation, and they show a good correlation $\left(r^{2}>0.97\right)$ for all systems. Almost all of the K added to the sand from free $\mathrm{KCl}$ was percolated within the 55 days period evaluated, and most (70-75\%) was released in the first five water additions.

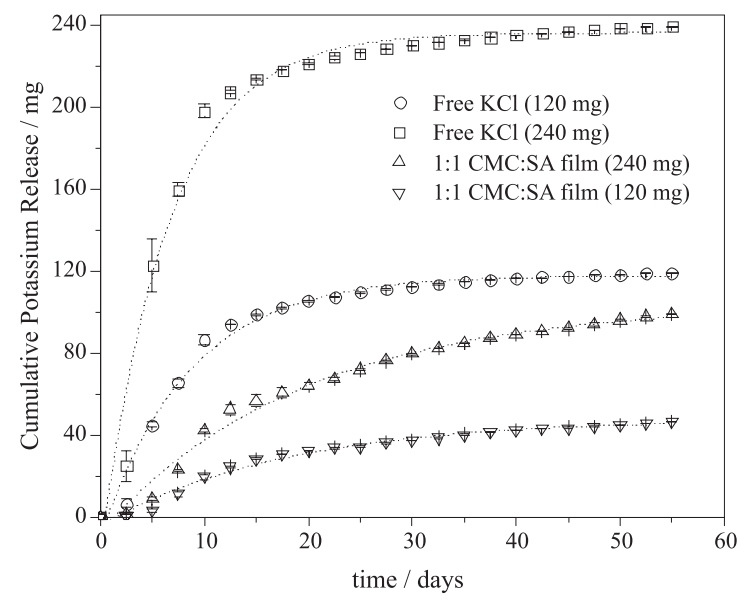

Figure 4. Release profiles of K (120 mg and $240 \mathrm{mg}$ ) from 1:1 CMC:SA films and free $\mathrm{K}$ in sand soil.

However, less than half ( 46 to $48 \%$ ) of the K incorporated into the 1:1 CMC:SA film was released after 55 days, and only around $20 \%$ was released in the first 5 percolations. This rate of $\mathrm{K}$ release from the films is much lower than that obtained from polyacrylamide hydrogels, where $60 \%$ of the fixed amount was released in the first $5 \mathrm{~h}{ }^{23} \mathrm{In}$ fact, the data reported herein suggest that it is possible to load different amounts of $\mathrm{K}$ in the same films without significant losses of this cation by leaching after the percolation process.

In summary, using the films it is possible to control the release of $\mathrm{K}$ according to the characteristics of plant uptake at different growing stages.
The release mechanisms for CMC, SA and 1:1 CMC:SA films were analyzed considering the power law equation (equation 2) and the diffusion coefficient determined using equation 3 . The power equation gave a very good fit in the case of SA and the 1:1 CMC:SA $\left(\mathrm{r}^{2}>0.99\right)$ but not for CMC $\left(r^{2}=0.9721\right)$. Comparing the $\mathrm{k}$ and $\mathrm{D}$ values (Table 1$)$ it is possible to observe that the release of $\mathrm{K}$ is very slow for the CMC and SA films, since the diffusion coefficient for 1:1 CMC:SA films was 2200 times higher than that for SA films, suggesting a significant change in the film properties according to the mixture components.

$$
\begin{aligned}
& \frac{M_{t}}{M_{\infty}}=\mathrm{k} \mathrm{t}^{\mathrm{n}} \\
& D=\frac{\mathrm{k}^{2} \pi l^{2}}{16}
\end{aligned}
$$

Considering the film morphology (Figure 2), it seems clear that the mixture of the two components gave a less dense and less homogeneous film which, in turn, favored the release process. As explained above in relation to the FTIR results, was not detected interactions in the CMC:SA mixture, suggesting that a more open structure was formed. Also, in a previous study it was demonstrated that the water permeation was higher in 1:1 CMC:SA films than in the pure systems. ${ }^{22}$ In addition, the swelling by water is largely favored by the presence of negative charges in polyelectrolyte systems, such as, CMC and SA. ${ }^{24,25}$ Considering that the films were obtained from solutions at $c a . \mathrm{pH} 7$, i.e., negatively charged systems were formed, the anion-anion repulsion was higher in 1:1 CMC:SA films than in the pure systems. Under this condition, a more open structure was formed, which in turn, favored the swelling of the 1:1 CMC:SA films, increasing, as consequence, the release process.

The release mechanism was evaluated through the release exponent (n), which is associated with the mechanism of $\mathrm{K}$ release and the polymeric matrix. For the pure polymeric systems (CMC and SA) the $\mathrm{n}$ values were higher than unity suggesting that besides the diffusion process, the release mechanism was associated with processes of swelling and erosion of the polymeric matrix. Thus, we believe the release process was first controlled by the permeation of water through the dense polymeric matrixes, as we can see by the micrographs in Figure 2, followed by the swelling and erosion (solubility) process due to the presence of water. For the 1:1 CMC:SA mixture, the $n$ values were 0.40 and 0.44 for films with 120 and $240 \mathrm{mg}$ of $\mathrm{K}$, respectively, suggesting a typical diffusion mechanism. As observed in the micrograph of Figure 2, the 1:1 CMC:SA film had a greater roughness and was more heterogeneous in comparison to the $\mathrm{CMC}$ and SA films. The infrared analysis suggested the absence of interactions between the components. Therefore, a more open 
Table 1. Kinetic parameters determined through power law model

\begin{tabular}{lcccc}
\hline System & $\begin{array}{c}\mathrm{k} \\
\left(\mathrm{day}^{-1}\right)\end{array}$ & $\mathrm{n}$ & $\mathrm{r}^{2}$ & $\begin{array}{c}\mathrm{D}\left(\times 10^{8}\right) \\
\left(\mathrm{cm}^{2} \mathrm{day}^{-1}\right)\end{array}$ \\
\hline CMC (120 mg) & 0.0057 & 1.10 & 0.9721 & 0.016 \\
SA (120 mg) & 0.0021 & 1.19 & 0.9950 & 0.002 \\
1:1 CMC:SA (120 mg) & 0.0948 & 0.40 & 0.9920 & 4.40 \\
1:1 CMC:SA (240 mg) & 0.0845 & 0.44 & 0.9967 & 3.50 \\
\hline
\end{tabular}

structure can be inferred. In this case, the water permeation was facilitated, favoring the diffusion of $\mathrm{K}$ through the films. The differences observed in the release processes are of particular interest for application as controlled systems for the release of $\mathrm{K}$ in soils, especially to feed crops grown on substrates with small amounts of negative charges.

\section{Conclusions}

The release of $\mathrm{K}$ from films based on sodium carboxymethylcellulose (CMC), sodium alginate (SA) and their 1:1 mixture to sand soil followed the order: 1:1 CMC:SA > CMC > SA, reflecting, in the case of the mixture, the morphology, the immiscibility between the components, the anion-anion repulsion and swelling of the film. A simple comparison of the K released from the films with the leaching process using free $\mathrm{K}$, suggests that the films can potentially be used as a controlled delivery system. In the case of $\mathrm{K}$, the rate of release from the films was particularly low, this being of interest in terms of controlling the delivery process according to the characteristics and different growing stages of plants, especially when cultivated in substrates with low negative charge. The release mechanism of $\mathrm{K}$ from the 1:1 CMC:SA mixture was controlled by a diffusion process, however, associated effects due to swelling and erosion of the matrix films, were observed for the pure CMC and SA systems.

\section{Acknowledgments}

This research was supported by the Conselho Nacional de Desenvolvimento Científico e Tecnológico (CNPq), by the Federal University of Santa Catarina (Universidade Federal de Santa Catarina - UFSC) and by the State University of Santa Catarina (Universidade do Estado de Santa Catarina UDESC), Brazil.

\section{References}

1. Pasparakis, G.; Boroupoulos, N.; Int. J. Pharm. 2006, 323, 34.

2. Brabuci, R.; Magnani, A.; Consuni, M.; Macromolecules 2000 , 33, 7475.

3. Xiao, C.; Lu Y.; Liu, H.; Zhang L.; J. Appl. Polym. Sci. 2001, $80,26$.

4. Dong, Z.; Wang, Q.; Du, Y.; J. Membr. Sci. 2006, 280, 37.

5. Çaykara, T.; Demirci, S.; Eroglu, M. S.; Güven, O.; Polymer 2005, 46, 10750

6. Russo, R.; Malinconico, M.; Petti, L.; Romano, G.; J. Polym. Sci., Part B: Polym. Phys. 2005, 43, 1205.

7. Aslani, P.; Kennedy, R. A.; J. Controlled Release 1996, 42, 75.

8. Pourjavardi, A.; Barzegar, S. H.; Mahdavinia, G. R.; Carbohyd. Polym. 2006, 66, 386.

9. Nie, H.; Liu, M.; Zhan, F.; Gou, M.; Carbohydr. Polym. 2004, $58,185$.

10. Bajpai, A. K.; Giri, A.; Carbohydr. Polym. 2003, 53, 271.

11. Kulkarni, A. R.; Soppimath, K. S.; Aminabhavi,T. M.; Dave, A. M.; J. Appl. Polym. Sci. 2002, 85, 911.

12. Kulkarni, A. R.; Soppimath, K. S.; Aminabhavia, T. M.; Dave, A. M.; Mehta, M. H.; J. Controlled Release 2000, 63, 97.

13. Isiklan, N.; J. Appl. Polym. Sci. 2006, 99, 1310.

14. Al-Musa, S.; Abu Fara, D.; Badwan, A. A.; J. Controlled Release 1999, 57, 223.

15. Chandra, R.; Rustgi, R.; Prog. Polym. Sci. 1998, 23, 1273.

16. Akelah, A.; Mater. Sci. Eng., C 1996, 4, 83.

17. Hanafi, M. M.; Eltaib, S.M.; Ahmad, M. B.; Eur. Polym. J. 2000, 36, 2081.

18. Choudhary, G.; Kumar, J.; Walia, S.; Parsad, R.; Parmar, B. S.; J. Agric. Food Chem. 2006, 54, 4727.

19. Adler, P. R., Wilcox, G.; Commun. Soil Sci. Plant Anal. 1985, 16,1153

20. Zhan, L. M.; Colloid Polym. Sci. 1999, 227, 886.

21. Alvarez-Lorenzo, C.; Duro, R.; Gómez-Amoza, J. L.; MartinézPacheco, R.; Souto, C.; Concheiro, A.; Colloid Polym. Sci. 2001, $279,1045$.

22. Oliveira, A. F.; Coelho, C. M. M.; Miqueloto, A.; Coimbra, J. L. M.; Soldi, V.; Quim. Nova 2009, 32, 1845.

23. Aouada, F. A.; Moura, M. R.; Menezes, E. A; Nogueira, A. R. A.; Mattoso, L. H. C.; Rev. Bras. Cienc. Solo 2008, 32, 1643.

24. Pourjavadi, A.; Barzegar, S.; Mahdavinia, G. R.; Carbohydr. Polym. 2006, 66, 386.

25. Fujimoto, J.; Petri, D. F. S.; Langmuir 2001, 17, 56.

Submitted: January 28, 2010 Published online: September 14, 2010 